\title{
Intensity-modulated radiation therapy in advanced head and neck patients treated with intensive chemoradiotherapy: Preliminary experience and future directions
}

\author{
MICHAEL T. MILANO ${ }^{1,6}$, EVERETT E. VOKES ${ }^{1-3}$, JOHNNY KAO ${ }^{1,7}$, WELLS JACKSON ${ }^{1}$, MARCY A. LIST ${ }^{3}$, \\ KERSTIN M. STENSON ${ }^{4}$, MARY ELLYN WITT ${ }^{1}$, ALLISON DEKKER ${ }^{1}$, ELLEN MacCRACKEN $^{5}$, \\ MICHAEL C. GAROFALO ${ }^{1,8}$, STEVEN J. CHMURA ${ }^{1}$, RALPH R. WEICHSELBAUM ${ }^{1,3}$ and DANIEL J. HARAF ${ }^{1}$ \\ Departments of ${ }^{1}$ Radiation and Cellular Oncology and ${ }^{2}$ Medicine, ${ }^{3}$ Cancer Research Center, \\ ${ }^{4}$ Department of Surgery, ${ }^{5}$ Center for Speech and Swallowing Disorders, University of Chicago, Chicago, \\ IL 60610; ${ }^{6}$ Department of Radiation Oncology, University of Rochester, Rochester, NY 14642; \\ ${ }^{7}$ Department of Radiation Oncology, Mount Sanai School of Medicine, New York, NY 10029; \\ ${ }^{8}$ Department of Radiation Oncology, University of Maryland, Baltimore, MD 21201, USA
}

Received April 14, 2005; Accepted May 30, 2005

\begin{abstract}
We review our recent experience with intensitymodulated radiation therapy (IMRT) and conventional threedimensional radiation therapy (C3DRT) in advanced head and neck cancer. Sixty-nine patients with Stage IV head and neck cancer (and stage III base of tongue and hypopharynx) enrolled in a Phase II study of definitive chemoradiation; 20 received all or part of their radiation with IMRT. Imageguided set-up, using video subtraction techniques, was used in all patients. Six weekly doses of induction carboplatin $(\mathrm{AUC}=2)$ and paclitaxel $\left(135 \mathrm{mg} / \mathrm{m}^{2}\right)$ were followed by alternating weekly chemoradiation to $75 \mathrm{~Gy}$ with $1.5 \mathrm{~Gy}$ BID fractions, concurrent with paclitaxel (100 mg/m²/week), 5-fluorouracil $\left(600 \mathrm{mg} / \mathrm{m}^{2} / \mathrm{d}\right)$ and hydroxyurea $(500 \mathrm{mg}$ PO BID). Two consecutive cohorts enrolled, differing in radiation scheme: 75 Gy to gross disease in both, 60 or 54 Gy to first echelon lymphatics and 45 or 39 Gy to second echelon lymphatics. With a median follow-up of 47 months, 3-year overall survival is $68.5 \%$ and 3-year locoregional control is $94.0 \%$, with no significant differences between those treated with C3DRT versus IMRT, nor between the two radiation dosing schemes. Actuarial overall survival without tracheostomy or laryngectomy, or without a gastrostomy tube was also similar. Acute mucositis, dermatitis and pain were similar with C3DRT and IMRT. Preliminary data suggests
\end{abstract}

Correspondence to: Dr Michael T. Milano, Department of Cellular and Radiation Oncology, University of Chicago, 5841 S. Maryland Ave., MC 9006, Chicago, IL 60637, USA

E-mail:mtmilano@yahoo.com

Key words: head and neck cancer, intensity-modulated radiation therapy, chemoradiation
IMRT is well tolerated, and does not compromise locoregional control, indicating that IMRT adequately covers the clinical volume at risk. Building on the present clinical experience, future directions include more directed efforts at reducing toxicity, with better planning software and planning techniques.

\section{Introduction}

Intensity-modulated radiation therapy (IMRT) is a means of delivering radiation dose in a more conformal manner than conventional three-dimensional radiation therapy (C3DRT). The physician delineates targets to treat and targets to avoid. More conformal dose delivery is accomplished by varying the radiation beams spatially and/or temporally (1). C3DRT is forward planned, with the field shapes and beam intensities determined prior to running the plan. In contrast, IMRT utilizes inverse planning, with the field modulation optimized by the planning software. IMRT is particularly well-suited for head and neck neoplasms for several reasons: there are critical structures in the head and neck (i.e. spinal cord, parotid glands and oral cavity) which might be spared from radiation toxicity by conforming delivery of dose (2-4); the head and neck can be relatively immobilized, and reproducibly positioned, ensuring quality control (5); and, because of normal tissue sparing and reproducible patient positioning, higher radiation doses can be administered. In a recent survey of members from the American Society for Therapeutic Radiation Oncology, of those using IMRT in their clinics, $87 \%$ treat head and neck cancer with IMRT (6).

We have participated in previously published multiinstitutional studies treating advanced head and neck cancer with induction cisplatin, 5-fluorouracil, leucovorin and $\alpha$-interferon followed by concurrent 5-fluorouracil and hydroxyurea with daily (1.8-2.0 Gy) C3DRT to a dose of 65-75 Gy (7-11). Treatment was administered for five days, followed by a nine-day rest period. Surgery of the primary tumor was 
generally reserved for residual disease, and neck dissection was recommended after chemoradiation for $\geq \mathrm{N} 2$ disease (12). Five-year locoregional control (LRC) was 70-78\%, distant control (DC) $>90 \%$, progression-free survival (PFS) $64-78 \%$ and overall survival (OS) 47-62\%. With nasopharyngeal cancer, 5-year LRC was 93\%, PFS 86\% and OS 77\% (11).

In a subsequent study, cisplatin, 5-fluorouracil and hydroxyurea were administered concurrently with twicedaily radiation (1.5 Gy $\mathrm{BID}$ ) to a dose of 70-75 Gy; while in later studies, concurrent paclitaxel, 5-fluorouracil and hydroxyurea (THF) were used (13-15). These regimens yielded OS and PFS similar to the preceding studies, with a higher LRC of $80-92 \%$. Induction chemotherapy was not utilized in these studies, as it was hypothesized that controlling local disease would result in better DC. However, distant metastasis developed in roughly $20 \%$, more than twice that seen in preceding trials. As more intensive chemotherapy may be necessary to control distant spread, induction chemotherapy was reintroduced in ensuing trials.

Induction carboplatin and paclitaxel, followed by TFH chemoradiation has yielded a 3-year PFS of $80 \%$ and OS of $70 \%$, and a 2-year LRC of $94-97 \%$ and DC of $93 \%(16,17)$. In May 1999, less than one year into this multi-institutional trial, the University of Chicago instituted IMRT treatment planning and delivery. We hypothesized that conformal radiation with IMRT would deliver an adequate dose to volumes at risk of failure with no compromise in locoregional control, and result in reduced acute and late toxicity by better sparing of normal tissue. This study reviews this experience with IMRT, and compares outcome and toxicity between C3DRT and IMRT.

\section{Patients and methods}

Patients with Stage IV (M0) squamous cell carcinoma, poorly differentiated carcinoma or lymphoepithelioma of the head and neck enrolled into a multi-institutional advanced head and neck protocol $(16,17)$. Patients with Stage III base of tongue and hypopharynx were also eligible based on poor prognosis. The protocol was approved by the institutional review boards of all participating institutions. All patients signed a written informed consent prior to treatment. Patients analyzed here were enrolled at the University of Chicago. A major goal of this trial was organ preservation. Surgery prior to chemoradiation was allowed for oral cavity and tonsillar primaries amenable to resection, without anticipated loss of function. Neck dissection was also allowed prior to chemoradiation.

Induction chemotherapy comprised 6-8 weeks of weekly carboplatin (intravenously over $30 \mathrm{~min}$, calculated AUC=2) and paclitaxel (intravenously over $3 \mathrm{~h}, 135 \mathrm{mg} / \mathrm{m}^{2}$ ). Radiation was then delivered on an alternating weekly schedule, with concurrent 5 -fluorouracil $\left(600 \mathrm{mg} / \mathrm{m}^{2} / \mathrm{d}\right.$ continuous infusion for 5 days), paclitaxel (100 mg/m² intravenously over $1 \mathrm{~h}$ every week) and hydroxyurea (500 mg orally twice daily), with each week of treatment comprising one cycle. Radiation was administered five days a week, twice-daily at 1.5 Gy per fraction, with fractions separated by $>6$ h. A 2 Gy daily fraction was allowed if the patient could only be treated once on a given day. Simultaneous integrated boosting was not employed (i.e. patients received the same dose with each treatment fraction, with subsequent cone-down boosts as described below).

The radiation dose was prescribed to a planning target volume (PTV), which was generated on the treatment-planning CT using AcQSim VoxelQ software (Philips Medical Systems, Cleveland $\mathrm{OH}$ ). The PTV encompassed the clinical target volume (CTV), representing gross tumor volume (GTV) plus microscopic disease. The GTV, which included gross primary and gross nodal disease, was determined from radiological studies and clinical examination, including tumor mapping under anesthesia. Microscopic disease included areas at risk for microscopic extension of the tumor as well as cervical lymphatics at risk for disease spread. The GTV and CTV were contoured directly onto each CT slice.

The initial CTV encompassed the GTV (volume expanded with $\sim 7-10 \mathrm{~mm}$ margins) and first and second echelon uninvolved lymph nodes. The initial target volume $\left(\mathrm{PTV}_{1}\right)$ was generated via a 3-mm volume expansion of the CTV. The PTV expansion of the CTV accounts for patient set-up uncertainty and organ motion (5). The subsequent boost target volume $\left(\mathrm{PTV}_{2}\right)$ encompassed the expanded GTV and first echelon uninvolved lymph nodes, again with a 3-mm volume expansion of the CTV. The final cone-down boost target volume $\left(\mathrm{PTV}_{3}\right)$ included the GTV with a volume expansion of $\sim 1 \mathrm{~cm}$.

After the volume expansion generated a PTV, the PTV was modified on each CT slice to avoid extension beyond skin and to avoid overlap with the spinal cord. For the latter, the PTV was adjusted such that the contour encompassed a narrow rim (several $\mathrm{mm}$ ) around the vertebral body. Volumes were entered by one radiation oncologist (DJH) in the same manner for IMRT and C3DRT plans.

In an initial cohort, prescribed doses were 45, 60 and 75 Gy to $\mathrm{PTV}_{1}, \mathrm{PTV}_{2}$, and $\mathrm{PTV}_{3}$ respectively (16). In a subsequent cohort, accruing after January 2000, doses were changed to 39,54 and 75 Gy respectively (17). The rationale for this change was based on the discovery that, in the first cohort, there were no failures in grossly uninvolved areas (16), and also based on the desire to reduce acute toxicity (17). The prescribed dose to microscopic, resected disease was $~ 60 \mathrm{~Gy}$ in both cohorts. Thus, patients who had no measurable disease (see below) received only 4 cycles of treatment.

A litecast, used for immobilization, was marked at the time of simulation to enable accurate alignment. Treatmentplanning CT scans (PQ5000 CT Simulator, Marconi Medical Systems, Cleveland, $\mathrm{OH}$ ) with intravenous contrast were obtained prior to and after induction chemotherapy. Using the AcQSim VoxelQ software package (Philips Medical Systems), image correlation was used to fuse the pre-induction scan with the post-induction scan. Thus, the pre-induction scan was used to help define the GTV on the post-induction CT scan. With complete or near complete response to induction and/or substantial weight loss during induction, the two scans would be substantially different. In these instances, efforts were made to recreate the original tumor as accurately as possible, with appropriate adjustments.

Prior to starting treatment, patients underwent set-up verification, at which time orthogonal images were obtained and compared to digitally reconstructed simulation films. 
Additionally, a video image was captured with the patient precisely aligned in the treatment position. On each subsequent treatment, real-time images of the patient were acquired and video subtraction techniques were used to enable an interactive image-guided patient set-up (5). Weekly lateral and anterior-posterior port films were also used to verify the isocenter. Patients were treated with a Varian 21EX linear accelator (Varian Associated, Palo Alto, CA). In most patients, a mid-treatment CT simulation scan was performed, with a new litecast, to correct for changes resulting from weight loss and/or tumor reduction. The resimulated CT scan was correlated to the initial treatment CT scan to assist in target delineation.

The first 15 patients enrolled were treated with C3DRT, after which IMRT was implemented. Patients were selected for IMRT-planning if time and resources were available, and if an adequate treatment plan (see below) could be obtained. Two patients planning to receive IMRT had difficulty remaining motionless in the litecast; because of the longer treatment times and the sharper dose fall-off with IMRT, these patients were instead treated with C3DRT in order to minimize the possibilty of underdosing the tumor (neither has failed). The last 9 patients enrolled were treated with C3DRT, during a CORVUS software upgrade. The relatively slow planning with IMRT prohibited the use of IMRT in all patients.

C3DRT plans were generated using PlanUNC. With C3DRT, the PTV was treated with opposed lateral $6 \mathrm{MV}$ photon fields, with a matched AP supraclavicular field as described previously $(13,14)$. Segmented fields were used to increase dose homogeneity. The spinal cord dose was kept below 39 Gy. High-energy electron fields were matched to anterior neck photon fields to boost the posterior neck.

With IMRT, $6 \mathrm{MV}$ photons were exclusively used. The entire PTV was treated with IMRT (as opposed to matching a supraclavicular AP field to the IMRT fields), thus eliminating high-dose regions that occur at field match lines (where dose heterogeneity can be $>150 \%$ ). IMRT plans were generated using commercial inverse planning software (CORVUS, version 3.0, NOMOS Corp.), which produces optimal intensitymodulated profiles using a simulated annealing algorithm. Dynamic multileaf collimators were used to shape fields. Multiple (7-9)-field coplanar plans were used, with fields evenly separated around a $360^{\circ}$ arc. If an adequate plan (see below) could not be achieved with a 9-field arrangement, a 7 -field arrangement was attempted (and was used in 5/20 patients). The dose-volume constraints of the target and normal tissues were defined. The spinal cord was strictly kept below 39 Gy. Radiation dose to the parotid glands (one or both) and oral cavity were minimized as much as possible without compromising target coverage.

The goal for mean parotid dose was dependent on the extent of nodal involvement, (i.e. how close clinically involved nodes approached the parotids). Unfortunately, precise calculations of the parotid mean doses and dose thresholds are not readily attainable for several compounding reasons: i) CORVUS ignores the region of overlap between expanded PTV and normal structures, requiring the dose matrix to be imported into other software to accurately calculate normal structure DVHs; ii) patients underwent 2 or more planning CT scans during treatment to correct for weight loss and tumor volume reduction; iii) nearly all patients received only a portion of their treatment with IMRT (see below); and iv) patients were treated with 3 different consecutive PTVs. Generally, the accepted mean parotid dose was $<35 \%$ of the prescribed dose to $\mathrm{PTV}_{1}$ and $\mathrm{PTV}_{2}$. With a portion of the treatment delivered by C3DRT (see below), this equates to the parotids in most patients receiving $\sim 50 \%$ of the total prescribed dose.

Most patients received their first week of treatment via C3DRT, which allowed time for IMRT-planning. The planning time with earlier versions of CORVUS was relatively slow, prohibiting upfront IMRT delivery in most patients, given the relatively short window $(\sim 1$ week) between the postinduction CT simulation and the start of radiotherapy, and the need to run multiple plans on each patient in order to optimize planning. Many patients received their boost dose via C3DRT; generally the final boost was delivered via C3DRT if the IMRT plan would have resulted in a cumulative spinal cord maximum $>39 \mathrm{~Gy}$. Since patients underwent two or more CT simulations, the cumulative spinal cord maxima were simply added, an admittedly stringent criteria since the worst case scenario of overlapping hot-spots was assumed. IMRT was delivered between $34-100 \%$ (mean $71 \%$, median $64 \%$ ) of the treatment. Table I outlines the IMRT treatment for each patient.

The IMRT plans were normalized to the $85 \%$ isodose line (i.e. $15 \%$ of the volume was planned to receive less than the prescription dose). The IMRT treatment plan was considered adequate if: a) no more than $2 \%$ of the prescribed volume received $>115 \%$ of the prescribed dose and b) there was no volume within the GTV or CTV receiving $<95 \%$ of the prescribed dose. For the latter, each CT scan slice was carefully examined to assure that there were no low dose regions within the GTV or CTV (i.e. the low dose regions were only at the periphery of the PTV). Multiple plans were run for each patient. If an adequate plan could not be achieved, C3DRT was used.

The Performance Status Scale for Head and Neck Cancer (PSS-HN) $(18,19)$ and Head and Neck Radiotherapy Questionnaire (20) were administered to assess late toxicity and quality of life.

All patients have been followed until recurrence or death. No patient was lost to follow-up. Survival and disease control parameters were calculated using Kaplan-Meier actuarial analyses, with survival and failure times defined from the first day of treatment until an event or date of last follow-up. PFS events included locoregional failure (LRF), distant failure (DF) and treatment-related death. Survival without a permament gastrostomy tube and survival without a permanent tracheostomy or laryngectomy were scored as failures if a patient required permanent intervention ( $G$ tube, tracheosotomy or laryngectomy) and/or died. Patients dying without evidence of disease recurrence were censored at the time of death in the analyses of PFS, time to LRF, and time to DF.

\section{Results}

Sixty-nine patients from the University of Chicago enrolled between November 1998 and January 2001, and were analyzed until February 2005. The mean and median follow-ups were 
Table I. Treatment parameters and outcome for 20 IMRT patients.

\begin{tabular}{|c|c|c|c|c|c|c|c|c|c|}
\hline Stage & Subsite & $\begin{array}{l}\text { Initial } \\
\text { C3DRT } \\
\text { dose }\end{array}$ & $\begin{array}{l}\text { IMRT } \\
\text { dose }\end{array}$ & $\begin{array}{l}\text { Final } \\
\text { C3DRT } \\
\text { dose }\end{array}$ & $\begin{array}{l}\text { Total } \\
\text { dose }\end{array}$ & $\begin{array}{c}\% \\
\text { IMRT }\end{array}$ & $\begin{array}{c}\text { Permanent } \\
\text { G-tube } \\
\text { placed }\end{array}$ & $\begin{array}{c}\text { Permanent } \\
\text { tracheostomy } \\
\text { placed }\end{array}$ & Outcome \\
\hline $\mathrm{T} 1 \mathrm{~N} 2 \mathrm{~b}$ & Hypopharynx & 15.0 & 24.5 & 33.5 & 73.0 & 34 & & & NED: alive \\
\hline T4N0 & Oral cavity & 15.0 & 29.0 & 17.5 & 61.5 & 47 & & & NED: dead (AML) \\
\hline T3N2c & Hypopharynx & 15.0 & 39.0 & 21.0 & 75.0 & 52 & & & NED: alive \\
\hline T4N0 & Hypopharynx & 15.0 & 39.0 & 21.0 & 75.0 & 52 & $7 \mathrm{M}$ & $7 \mathrm{M}$ & $\begin{array}{c}\text { NED: dead } \\
\text { (choking on food) }\end{array}$ \\
\hline T4N2b & Hypopharynx & 15.0 & 39.0 & 19.5 & 73.5 & 53 & $\begin{array}{l}\text { During } \\
\text { induction }\end{array}$ & & NED: alive \\
\hline T4N0 & Hypopharynx & 15.0 & 39.5 & 18.5 & 73.0 & 54 & & & NED: alive \\
\hline T4N0 & Larynx & 15.0 & 42.0 & 15.0 & 72.0 & 58 & & & NED: alive \\
\hline T4N1 & Larynx & 15.0 & 43.5 & 15.0 & 73.5 & 59 & & & NED: alive \\
\hline $\mathrm{T} 2 \mathrm{~N} 2 \mathrm{~b}$ & Oropharynx & 15.0 & 45.0 & 14.0 & 74.0 & 61 & & & NED: alive \\
\hline T4N2c & Larynx & 15.0 & 45.0 & 12.5 & 72.5 & 62 & $\begin{array}{l}\text { During } \\
\text { radiation }\end{array}$ & $\begin{array}{l}\text { Before } \\
\text { induction }\end{array}$ & $\begin{array}{l}\text { NED: dead (multiple } \\
\text { medical problems) }\end{array}$ \\
\hline $\mathrm{T} 2 \mathrm{~N} 2 \mathrm{~b}$ & Oral cavity & 15.0 & 39.0 & 6.0 & 59.0 & 66 & $1 \mathrm{M}$ & & NED: alive \\
\hline T1N2a & Oropharynx & 15.0 & 46.0 & 0 & 61.0 & 75 & & & NED: alive \\
\hline TxN3 & $\begin{array}{l}\text { Unknown } \\
\text { primary }\end{array}$ & 15.0 & 58.0 & 0 & 73.0 & 79 & $7 \mathrm{M}$ & & $\mathrm{DF} 4 \mathrm{M}$ \\
\hline $\mathrm{T} 2 \mathrm{~N} 2 \mathrm{a}$ & Oropharynx & 15.0 & 59.0 & 0 & 74.0 & 80 & & & NED: alive \\
\hline T3N2a & Hypopharynx & 15.0 & 59.0 & 0 & 74.0 & 80 & & & NED: alive \\
\hline T4N0 & Oropharynx & 15.0 & 60.0 & 0 & 75.0 & 80 & & $\begin{array}{c}\text { Before } \\
\text { induction }\end{array}$ & NED: alive \\
\hline T4N0 & $\begin{array}{l}\text { Suprglottic } \\
\text { larynx }\end{array}$ & 15.0 & 60.0 & 0 & 75.0 & 80 & & & $\begin{array}{l}\text { Treatment-related } \\
\text { death at } 9 \mathrm{M}\end{array}$ \\
\hline $\mathrm{T} 4 \mathrm{~N} 2 \mathrm{~b}$ & Oropharynx & 15.0 & 60.0 & 0 & 75.0 & 80 & & & $\begin{array}{c}\text { NED: dead } \\
\text { (seizure disorder) }\end{array}$ \\
\hline T4N3 & Oropharynx & 14.0 & 58.0 & 0 & 72.0 & 81 & & $38 \mathrm{M}$ & NED: alive \\
\hline T1N2a & Oropharynx & 0 & 74.0 & 0 & 74.0 & 100 & & & NED: alive \\
\hline
\end{tabular}

The initial C3DRT dose was given in the first week of treatment, prior to IMRT delivery. The final C3DRT dose was given after IMRT delivery. The listed doses do not correspond to doses administered to PTV1-3. For example, 19 patients received 39-45 Gy to PTV1, in which 14-15 Gy was given by C3DRT. \% IMRT, percent of total dose delivered via IMRT. M, months post-chemoradiotherapy. NED, no evidence of disease. Doses in Gy.

42.6 and 47.0 months respectively. C3DRT was used in 49 patients (median follow-up of 45.5 months) and IMRT in 20 (median follow-up 51.4 months). All living patients were followed for at least 2 years.

The patient characteristics are outlined in Table II. All patients had an ECOG performance status of 0-1. The two groups are comparable, except there are significantly more patients with hypopharyngeal cancer (a subsite which tends to have a poorer outcome) in the IMRT group (30\% versus $4.3 \%, \mathrm{p}=0.006)$. Table III outlines the surgical procedures performed. The goal of this trial was organ preservation; only $13 \%$ were treated with no measurable disease. Neck dissections were performed after chemoradiation in 29 patients with N2-3 disease. None of these patients had pathological residual disease. This contrasts with our earlier experience, in which $\sim 35 \%$ of $\mathrm{N} 2-3$ patients (mostly $\geq \mathrm{N} 2 \mathrm{~b}$ ) had pathologic residual disease after post-chemoradiation neck dissection $(12,15)$.

Acute toxicity. Table IV lists the acute chemoradiation toxicities. There are no significant differences in acute 
Table II. Patient characteristics.

\begin{tabular}{|c|c|c|c|}
\hline & All patients & C3DRT & IMRT \\
\hline No. of patients & 69 & 49 & 20 \\
\hline Age range (years) & $36.4-76.82$ & $36.4-76.8$ & $38.0-67.7$ \\
\hline Median & 57.9 & 58.6 & 57.4 \\
\hline Mean & 56.8 & 57.6 & 55.0 \\
\hline Follow-up (months) & $4.5-74.5$ & $4.5-74.5$ & 7.4-69.3 \\
\hline Median & 47.0 & 45.5 & 51.4 \\
\hline Mean & 42.6 & 42.9 & 42.1 \\
\hline Mean (living) & 55.4 & 57.1 & 55.0 \\
\hline \multicolumn{4}{|l|}{$\begin{array}{l}\text { Radiation dose } \\
\text { scheme }^{\mathrm{b}}\end{array}$} \\
\hline Scheme 1 & 35 & 25 & 10 \\
\hline Scheme 2 & 34 & 24 & 10 \\
\hline \multicolumn{4}{|l|}{ Gender } \\
\hline Male & 51 & 36 & 15 \\
\hline Female & 18 & 13 & 5 \\
\hline \multicolumn{4}{|l|}{ Site } \\
\hline Nasopharynx & 2 & $2(4.3)$ & 0 \\
\hline Hypopharynx & 8 & $2(4.3)$ & $6(30.0)$ \\
\hline Larynx & 14 & $10(20.4)$ & $4(20.0)$ \\
\hline Oropharynx & 33 & $26(53.1)$ & $7(35.0)$ \\
\hline Oral Cavity & 7 & $5(10.2)$ & $2(10.0)$ \\
\hline Unknown primary & 5 & $4(8.2)$ & $1(5.0)$ \\
\hline \multicolumn{4}{|l|}{ T Stage $^{\mathrm{a}}$} \\
\hline $\mathrm{X}$ & 5 & $4(8.5)$ & $1(5.0)$ \\
\hline $1-2$ & 16 & $10(21.3)$ & $6(30.0)$ \\
\hline $3-4$ & 46 & $33(70.2)$ & $13(65.0)$ \\
\hline \multicolumn{4}{|l|}{ N Stage ${ }^{a}$} \\
\hline $0-1$ & 20 & $13(27.7)$ & $7(35.0)$ \\
\hline 2 & 38 & $27(57.4)$ & $11(55.0)$ \\
\hline 3 & 9 & $7(14.9)$ & $2(10.0)$ \\
\hline \multicolumn{4}{|l|}{1997 AJCC Stage } \\
\hline \multicolumn{4}{|l|}{ Group } \\
\hline III & 3 & 3 & 0 \\
\hline IV & 66 & 46 & 20 \\
\hline
\end{tabular}

Numbers in parenthesis represent percentage of patients. ${ }^{\text {aExcludes }}$ the two nasopharynx patients in C3DRT group: T1N3a and T2aN3a. ${ }^{\mathrm{b}} \mathrm{See}$ text for doses to PTVs.

dermatitis, mucositis or pain between IMRT and C3DRT. There is significantly less grade $3-4$ dermatitis $(\mathrm{p}=0.046)$ in the cohort treated with less radiation to first and second echelon lymph nodes.

Clinical outcome. There were 6 deaths in the IMRT group: 1 from cancer, 1 from treatment toxicity and 4 intercurrent. The cancer death occurred at 23.6 months in a TxN3 patient who developed DF at 7.6 months. The toxic death occurred at 12.6 months in a patient with T4N0 tonsil cancer, who
Table III. Surgical therapy.

\begin{tabular}{lccc}
\hline & All patients & C3DRT & IMRT \\
\hline Number of patients & 69 & 49 & 20 \\
Neck dissection or & & & \\
excisional biopsy & & & \\
None & 30 & 20 & 10 \\
$\quad \%$ which were N2-3 & $37 \%$ & $35 \%$ & $40 \%$ \\
Before treatment & & & \\
LND: & 7 & 4 & 3 \\
Excisional biopsy & 2 & 1 & 1 \\
After treatment & & & \\
$\quad$ Unilateral LND & 22 & 17 & 5 \\
Bilateral LND & 8 & 7 & 1 \\
$\quad$ Neck biopsy only & 1 & 1 & 0
\end{tabular}

Pre-treatment surgery

of the primary

Tonsillectomy

Other $^{\mathrm{a}}$

No measurable disease

before chemoradiation

After primary surgery

+ LND

After LND (unknown

primary)

Total

6

3

3

3

3

0

Numbers in parenthesis represent percentage of patients. ${ }^{\text {IIncludes a }}$ wide local excision of a T2 buccal mucosal lesion and a mandibulectomy for a T4 floor of mouth cancer in the IMRT group, and a partial glossectomy for a $\mathrm{T} 2$ tongue cancer in the C3DRT group. These 3 patients, and 3 of 6 patients who had a tonsillectomy, also had a neck dissection prior to treatment.

developed radiation necrosis and carotid blow-out. A patient with T4N0 pyriform sinus cancer died while choking on food (though the patient had no medical clearance for oral intake after being unable to swallow during an oropharyngeal motility test). One developed acute myleogenous leukemia at 20 months and died 6 months later. Two others died at 7.4 and 17.3 months from comorbid illnesses. There were no LRF. Table I outlines the outcome of the IMRT patients.

There were 16 deaths in the C3DRT group: 6 from cancer, 1 from sepsis 1 week after completing treatment, 4 from second primary cancers (2 lung, esophagus and pancreas) and 5 intercurrent (sepsis at 33 months, car accident and 3 from comorbid illnesses). There were 6 failures, all of whom died from disease: $2 \mathrm{DF}$ only, $2 \mathrm{LRF}$ alone (at sites of original gross disease in a T4N0 oropharynx and T3N2B tonsillar cancer with simultaneous primary and nodal failures) and 2 LRF which later developed DF (positive post-treatment biopsies at the primary sites in a T4N2c oropharynx cancer and T4N2c supraglottic cancer). 
Table IV. Acute toxicity.

\begin{tabular}{|c|c|c|c|c|c|}
\hline & All patients & C3DRT ${ }^{\mathrm{a}}$ & IMRT & Scheme 1 & Scheme 2 \\
\hline No. of patients & 68 & 48 & 20 & 34 & 34 \\
\hline \multicolumn{6}{|l|}{ Mucositis } \\
\hline Grade 2 & (19.1) & (20.8) & $(15.0)$ & (14.7) & $(23.5)$ \\
\hline Grade 3 & (79.4) & (79.2) & $(80.0)$ & (85.3) & (73.5) \\
\hline Grade 4 & $(1.5)$ & $(0)$ & $(5.0)$ & $(0)$ & $(2.9)$ \\
\hline \multicolumn{6}{|l|}{ Dermatitis } \\
\hline Grade $0-1$ & (17.6) & (18.8) & $(15.0)$ & $(5.9)$ & $(29.4)$ \\
\hline Grade 2 & $(42.6)$ & (45.8) & $(35.0)$ & (41.2) & (44.1) \\
\hline Grade 3 & $(25.0)$ & $(25.0)$ & $(25.0)$ & (35.3) & (14.7) \\
\hline Grade 4 & (14.7) & (10.4) & $(25.0)$ & (17.6) & (11.8) \\
\hline \multicolumn{6}{|l|}{ Pain } \\
\hline Grade $0-1$ & (10.3) & (10.4) & $(10.0)$ & (11.8) & (26.5) \\
\hline Grade 2 & (17.6) & (12.5) & $(30.0)$ & (38.3) & $(44.1)$ \\
\hline Grade 3 & $(47.1)$ & $(50.0)$ & $(40.0)$ & (41.2) & $(26.5)$ \\
\hline Grade 4 & $(25.0)$ & $(27.1)$ & $(20.0)$ & $(8.8)$ & $(2.9)$ \\
\hline
\end{tabular}

Numbers in parenthesis represent percentage of patients. ${ }^{a}$ Excludes one C3DRT patient treated with radiation alone.

Table V. Clinical outcome.

All patients C3DRT IMRT p-value

Number

69

49

20

Overall survival

(OS) $(\%)$

1 year

3 year

$\begin{array}{llll}97.1 & 98.0 & 95.0 & \\ 68.5 & 68.1 & 69.6 & >0.5\end{array}$

Progression-free

survival (\%)

$$
1 \text { year }
$$

3 year

92.5

91.7

94.7

$\begin{array}{lll}88.0 & 87.3 \quad 89.5\end{array}$

$>0.5$

Locoregional

control (\%)

\begin{tabular}{|c|c|c|c|c|}
\hline 1 year & 95.5 & 93.8 & 100 & \\
\hline 3 year & 94.0 & 91.6 & 100 & 0.20 \\
\hline \multicolumn{5}{|c|}{ Distant control (\%) } \\
\hline 1 year & 94.0 & 93.8 & 94.7 & \\
\hline 3 year & 92.4 & 91.5 & 94.7 & $>0.5$ \\
\hline \multicolumn{5}{|c|}{$\begin{array}{l}\text { OS without a } \\
\text { tracheostomy or } \\
\text { laryngectomy }(\%)\end{array}$} \\
\hline 1 year & 84.1 & 85.7 & 80.0 & \\
\hline 3 year & 64.1 & 64.0 & 64.6 & $>0.5$ \\
\hline \multicolumn{5}{|c|}{$\begin{array}{l}\text { OS without a } \\
\text { gastrostomy } \\
\text { tube }(\%)\end{array}$} \\
\hline 1 year & 79.7 & 83.7 & 70.0 & \\
\hline 3 year & 64.5 & 66.3 & 60.0 & $>0.5$ \\
\hline
\end{tabular}

${ }^{\mathrm{a} C a l c u l a t e d}$ using log-rank test.
Table V summarizes the 1-year and 3-year OS, LRC and DC. There are no differences between the two radiation schemes (data not shown). Comparing IMRT versus C3DRT, there is a nonsignificant trend toward improved LRC $(\mathrm{p}=0.20)$ with IMRT. Certainly, IMRT delivered an adequate dose to the clinical volume at risk, with no compromise in locoregional control.

Late toxicity. The 3-year survival without a laryngectomy or permanent tracheostomy (in place at last follow-up) was $64.6 \%$ in the IMRT group and 64.0\% in the C3DRT group ( $>>0.5)$. Table VI details the tracheostomy placement in all patients. Of the IMRT patients, 2 long-term survivors were left with a permanent tracheostomy: one with T4N0 oropharynx cancer, in whom the tracheostomy was placed before treatment, and another with T4N3 oropharynx cancer who had a tracheostomy at 3.5 years for obstructive sleep apnea. Of the C3DRT patients, 3 long-term survivors were left with a permanent tracheostomy: one with a T3N2b larynx cancer, in whom the tracheostomy was placed 7 months after treatment; another with a T4N1 larynx cancer, in whom the tracheostomy was placed before treatment; and a patient who had a tracheostomy placed $>4$ years after treatment following extensive surgery for osteoradionecrosis. One patient underwent a total laryngectomy 4.5 years after treatment after developing a radiation-induced sarcoma. Additionally, a patient with T4N2c larynx cancer underwent a laryngectomy after LF and later died. There are no significant differences between the two radiation schemes in terms of survival without a laryngectomy or tracheostomy survival without a $G$ tube (data not shown).

The 3-year survival without a permanent gastrosotomy (G) tube (in place at last follow-up) was $60.0 \%$ in the IMRT group and $66.3 \%$ in the C3DRT group $(\mathrm{p}>0.5)$. Table VII details the G-tube placement in all patients. Of the IMRT 
Table VI. Tracheostomy and laryngectomy.

\begin{tabular}{|c|c|c|c|c|}
\hline & All patients & C3DRT & IMRT & p-value ${ }^{a}$ \\
\hline No. of patients & 69 & 49 & 20 & \\
\hline Tracheostomy before treatment & 9 & 4 & 5 & \\
\hline Subsequently removed & 7 & 3 & 4 & \\
\hline Persistent until death (<2-year survival) & 0 & 0 & 0 & \\
\hline Persistent until death (>2-year survival) & 0 & 0 & 0 & \\
\hline Present in long-term survivor & 2 & 1 & 1 & \\
\hline Early tracheostomy (during and $\leq 6$ months after treatment) & 8 & 6 & 2 & \\
\hline Subsequently removed & 3 & 2 & 1 & \\
\hline Persistent until death (<2-year survival) & 4 & 3 & 1 & \\
\hline Persistent until death (>2-year survival) & 0 & 0 & 0 & \\
\hline Present in long-term survivor & 1 & 1 & 0 & \\
\hline Late tracheostomy ( $>6$ months after treatment) & 5 & 3 & $2^{\mathrm{b}}$ & \\
\hline Subsequently removed & 1 & 1 & 0 & \\
\hline Persistent until death (<2-year survival) & 2 & 1 & 1 & \\
\hline Persistent until death (>2-year survival) & 0 & 0 & 0 & \\
\hline Present in long-term survivor & 2 & 1 & 1 & \\
\hline Laryngectomy & 2 & $2^{\mathrm{c}}$ & 0 & \\
\hline Tracheostomy or laryngectomy at $>24$ months & $6 / 54(11.1)$ & $4 / 39(10.3)$ & $2 / 15(13.3)$ & $>0.5$ \\
\hline
\end{tabular}

Numbers in parenthesis represents percentage of patients. ${ }^{\mathrm{a} C a l c u l a t e d}$ using Fisher's exact test. ${ }^{\mathrm{b}}$ This was the second tracheostomy for one of these patients; the first tracheostomy was previously removed. ${ }^{\circ}$ One patient is a long term survivor, while the other was an early death.

Table VII. Gastrostomy (G)-tube placement.

\begin{tabular}{|c|c|c|c|c|}
\hline & All patients & C3DRT & IMRT & p-value ${ }^{a}$ \\
\hline Number of patients & 69 & 49 & 20 & \\
\hline G tube placed before treatment & 9 & 7 & 2 & \\
\hline Subsequently removed & 6 & 6 & 0 & \\
\hline Persistent until death (<2-year survival) & 2 & 1 & 1 & \\
\hline Persistent until death ( $>2$-year survival) & 1 & 0 & 1 & \\
\hline Present in long-term survivor & 0 & 0 & 0 & \\
\hline G tube placed early (during and $\leq 6$ months after treatment) & 33 & 22 & 11 & \\
\hline Subsequently removed & 22 & 16 & 6 & \\
\hline Persistent until death (<2-year survival) & 6 & 3 & 3 & \\
\hline Persistent until death ( $>2$-year survival) & 3 & 3 & 0 & \\
\hline Present in long-term survivor & 2 & 0 & 2 & \\
\hline G tube placed late ( $>6$ months after treatment) & 4 & $2^{\mathrm{b}}$ & 2 & \\
\hline Subsequently removed & 1 & 0 & 1 & \\
\hline Persistent until death (<2-year survival) & 1 & 0 & 1 & \\
\hline Persistent until death ( $>2$-year survival) & 0 & 0 & 0 & \\
\hline Present in long-term survivor & 2 & 2 & 0 & \\
\hline Refused $\mathrm{G}$ tube against medical advice & 1 & 1 & 0 & \\
\hline G tube at $>24$ months & $8 / 54(14.8)$ & $5 / 39(12.8)$ & $3 / 15(20.0)$ & $>0.5$ \\
\hline
\end{tabular}

Numbers in parenthesis represents percentage of patients. ${ }^{\mathrm{a} C a l c u l a t e d ~ u s i n g ~ F i s h e r ' s ~ e x a c t ~ t e s t . ~}{ }^{\mathrm{b}}$ This was the second G tube in both patients; the first $\mathrm{G}$ tube was previously removed in both. 
patients, 2 long-term survivors were left with a permanent G tube: one patient with a T4N2b hypopharynx cancer who had severe swallowing dysfunction and aspiration prior to treatment, and another with $\mathrm{T} 2 \mathrm{~N} 2 \mathrm{~b}$ oral cavity cancer who developed esophageal strictures post-treatment. Of the C3DRT patients, 2 long-term survivors were left with a permanent $G$ tube: one with $\mathrm{T} 3 \mathrm{~N} 2 \mathrm{c}$ oropharynx cancer who developed swallowing impairment after treatment; and another who had a $\mathrm{G}$ tube placed afer developing a radiation-induced sarcoma (see above). Another patient with T3N2c oropharyngeal cancer refused a $\mathrm{G}$ tube 1.5 years after completing therapy, despite an oropharyngeal motility study demonstrating severe swallowing impairment.

Two C3DRT patients who developed soft tissue necrosis, including one who had a tracheostomy for laryngeal necrosis and another who had a poorly healing neck wound, were managed medically. Two C3DRT patients developed osteonecrosis: one underwent extensive mandibular reconstruction and another underwent hyperbaric oxygen treatment. Two IMRT patients developed soft tissue necrosis, including one who developed wound dehiscence after a post-operative neck dissection. Another developed fatal necrosis as described above.

At 1-year follow-up, quality of life and performance data were available on 14/19 IMRT and 37/48 C3DRT patients. There was no significant difference between groups with respect to the types of foods patients could eat (Normalcy of Diet scale on PSS-HN), with roughly $40 \%$ in both groups reporting dietary restrictions (i.e. soft diet, puree foods, liquids or tube feeding). Moderate to severe swallowing difficulty was reported in $29 \%$ of IMRT patients versus $20 \%$ of C3DRT patients $(\mathrm{p}=0.53)$, with similar percentages reporting chewing difficulty. Moderate to severe dry mouth was reported in $40 \%$ of patients in both groups. Moderate to severe sticky saliva was reported in 55\% of C3DRT patients versus $38 \%$ of IMRT patients $(\mathrm{p}=0.32)$. Significantly more IMRT patients reported moderate to severe hoarseness $(36 \%$ versus $10 \%$, $\mathrm{p}=0.04)$. Virtually all patients (96\% in IMRT group and $94 \%$ in C3DRT group) had completely understandable speech.

Of the 4 C3DRT patients treated below $62 \mathrm{~Gy}$, there were no permanent $G$ tubes or tracheostomies. Two of these patients developed xerostomia. One IMRT patient treated to 59 Gy has a permanent $\mathrm{G}$ tube, while 2 others treated below 62 Gy have no late toxicities. Of the 9 IMRT patients who received at least $75 \%$ of their dose from IMRT, no patients are G-tube dependent, and only 1 is G-tube assisted.

\section{Discussion}

The present study compares LRC of IMRT to C3DRT in patients with advanced head and neck cancer treated definitively with induction chemotherapy and hyperfractionated chemoradiotherapy. The rationale for induction chemotherapy in advanced head and neck cancer stems from organ preservation trials for laryngeal $(21,22)$ and oropharyngeal cancer (23), as well as our multi-institutional experience of poor DC in patients treated with chemoradiation without induction. Concurrent chemoradiotherapy has been shown to improve LRC, PFS and OS over radiation alone in multiple randomized trials (24-34). Several of these studies used twice daily radiation $(24,26,27,30)$. Twice daily radiation (81.6 Gy in 1.2 Gy BID fractions) afforded improved LRC compared to daily radiotherapy (70 Gy in 2 Gy fractions) in an RTOG study, in which chemotherapy was not used (35). The use of a week-on/week-off chemoradiation for advanced head and neck cancer was pioneered by our institution, and has yielded promising LRC and OS (7-15,36,37). An RTOG study has corroborated these results (38). After 1993, hyperfractionated (1.5 Gy BID) week on/week off chemoradiation was implemented (13-15). With induction carboplatin and paclitaxel, followed by THF chemoradiotherapy, we have maintained excellent 2-year LRC (94\%-97\%) and DC (93\%) $(16,17)$.

With our intensive chemoradiotherapy regimen, acute toxicity was not significantly different between IMRT and C3DRT (Table IV). The oral cavity (or portion of oral cavity not in the PTV) was entered as an avoidance structure, but did not seem to impact rates of acute mucositis. Most ( $80 \%)$ patients developed grade 3 mucositis. Perhaps with our chemoradiotherapy regimen, the threshold dose of mucositis is well below that which is delivered. Interestingly, skin toxicity was reduced in the second cohort treated with lower doses to uninvolved regional lymphatics. Though we did not assign skin as an avoidance structure, we did not find worse skin toxicity with IMRT. Lee and coworkers have shown a reduction in skin toxicity by defining the skin of the neck as a sensitive structure (39).

LRC with IMRT is dependent upon adequate PTV coverage, which relies upon knowledge of the tumor as well as areas at risk of spread (40-42). A unique aspect of IMRT raises concerns about its efficacy: volumes of tissue that receive a substantial fraction of the prescribed dose with C3DRT are selectively not treated with IMRT. However, the efficacy of IMRT is supported by the absence of LRF in the 20 patients in this study. IMRT-planning adequately delivered doses to areas at risk of locoregional failure.

Washington University published extensive treatment guidelines and outcomes for definitive (52 patients) and postoperative (74 patients) IMRT treatment planning $(41,43,44)$. Ten percent of patients had stage I-II cancer. Concurrent cisplatin based chemotherapy was given to $67 \%$ of the definitively treated patients. With definitive IMRT, 2-year LRC was $79 \%$ (after salvage, $84 \%$ ). With post-operative IMRT, 2-year LRC was 90\% (after salvage, 93\%).

In another study, LRC with IMRT was compared to C3DRT in patients with early and advanced oropharyngeal cancer (45). Concurrent cisplatin based chemotherapy was given to $75 \%$ of the 12 definitively-treated IMRT patients versus $5 \%$ of the 153 definitively-treated C3DRT patients. No differences in acute toxicity were seen. Aside from improved late xerostomia in the IMRT group, late complications were similar in both groups. For IMRT and C3DRT, the 2-year LRC was $88 \%$ versus $68 \%$ (NS), and 2-year PFS was $80 \%$ versus $58 \%(\mathrm{p}=0.002)$. The 2-year LRC for post-operativelytreated patients was $100 \%$ versus $76 \%$ (NS), and 2-year PFS was $92 \%$ versus $74 \%(\mathrm{p}=0.008)$.

The University of Michigan reported 2-year LRC in 79\% of 58 patients with advanced head and neck cancer treated with IMRT (4). Seventy-one percent of patients were treated post-operatively; $27 \%$ received induction chemotherapy and $26 \%$ received platinum-based chemoradiation. Of the 12 
patients who developed LRF, none failed in the high jugular lymph nodes (deep to the parotid glands), which were partially spared from radiation dose.

UCSF reported excellent 4-year LRC (97\%) and OS (88\%) in 67 patients with Stage I-IV nasopharyngeal cancer treated with IMRT $(46,47)$. In an extensive review of the UCSF IMRT experience with 150 patients, the 2-year LRC was 97\% with definitive treatment and $83 \%$ with post-operative treatment (48). Baylor University employs simultaneous accelerated boost IMRT (49); they reported 2 LF and 2 DF in 25 patients with Stage III-IV disease who were complete responders to IMRT (50).

The University of Michigan has pioneered the use of segmental IMRT with the goal of sparing major salivary glands and oral cavity $(2,51)$. Significant sparing of parotid function was seen, with a threshold mean parotid dose of 26 Gy. Washington University also modeled parotid sparing, demonstrating a threshold dose of $~ 32$ Gy for improved subjective and objective salivary function (52). However, in that study, neither radiation technique (IMRT vs. non-IMRT) nor the addition of chemotherapy impacted salivary functioning. The data from Michigan and Washington University were not published when patients were first enrolled in our study. In our study, parotid sparing techniques were used, with mean target doses of 30-35 Gy. Lower fraction size, as delivered in our study, could feasibly increase the threshold mean parotid dose. However, we did not find significant differences between IMRT and C3DRT in subjective late xerostomia.

Unlike Eisbruch and Chao, we did not objectively measure salivary flow, and have not rigorously correlated parotid radiation dose to salivary function. Additionally, most of our patients received only a portion of radiation by IMRT. More IMRT patients reported moderate to severe voice hoarseness (36\% versus $10 \%$ ), reflecting the greater percentage of hypopharyngeal patients in the IMRT group (30\% versus $6 \%$ ). Survival without a permanent $\mathrm{G}$ tube or without a permanent tracheostomy is similar in both groups. Most patients dependent on a $\mathrm{G}$ tube and/or tracheostomy at last follow-up had terminal disease (cancer-related or intercurrent). Late swallowing and respiratory complications arise not only from treatment, but also from permanent changes caused by the cancer. These factors confound the analysis of late G-tube and tracheostomy dependence.

The present study is novel in that all patients had advanced disease treated with induction chemotherapy and chemoradiation, and all head and neck sites were included. There are inherent weaknesses in our analyses. This is a small series in which patients were not randomized or stratified, and patients treated with IMRT were selected on the basis of availability of resources and achieving an acceptable plan. Hence, selection biases (in favor or against IMRT) are possible. Secondly, this study was not designed to discriminate differences between IMRT and C3DRT. Also, the number of failures in our entire cohort is small, which argues strongly for intensive chemoradiation in advanced head and neck cancer, but limits comparison between IMRT and C3DRT. Perhaps with such intensive therapy, subtle differences in radiation therapy may not contribute to large differences in outcome that would be possible to detect in such a small group of patients.
The patients presented here were among the first to be treated on our multi-institutional protocols with IMRT. With increased experience, and newer planning software the efficiency and adequacy of IMRT planning is improving, allowing us to assess multiple plans for each patient.

Since the PTV expansion of the contoured CTV requires extensive and time-consuming modifications of the expanded PTV near the skin and spinal cord, the PTV is now entered directly onto the CT scan slices. We continue to volume expand the GTV (by roughly $1-1.5 \mathrm{~cm}$ ), which may entail reducing this expansion off of the skin and spinal cord, and then we enter the PTVs, which always encompass the expanded GTV. This approach necessitates an understanding of how a volume expansion not only affects the expansion on axial slices but also in the caudal and cephalad directions.

We now separate the spinal cord into multiple levels along the cranial-caudal axis, and assign dose constraints accordingly. For example, during the planning of PTV1 and PTV2, more stringent constraints are placed upon the portion of spinal cord that traverses through CT scan slices with $\mathrm{PTV}_{3}$. As a result, our previous practice of adding spinal cord maxima from two planning CT scans to determine the maximum cord dose (described in Patients and methods) is now less stringent, since maxima are added from the appropriate cord level as opposed to the entire length of spinal cord. Thus, IMRT boost plans that previously would have been rejected in favor of C3DRT (because of concern over spinal cord dose) are now acceptable.

With newer versions of CORVUS, dose homogeneity in the IMRT plans is improving. In nearly all advanced head and neck cancer patients, adequate 9-field IMRT plans are now achieved, and IMRT is delivered throughout the entire radiation course. We are now also able to more accurately calculate parotid dose.

Because of the promising locoregional control in the two initial cohorts of this Phase II study $(16,17)$, the last cohort (not analyzed in the present report) was treated with further dose reductions $\left(36,51\right.$ and 72 Gy to $\mathrm{PTV}_{1}, \mathrm{PTV}_{2}$, and $\mathrm{PTV}_{3}$ respectively) in an effort to diminish toxicity (53). Nearly all of these patients were treated with IMRT. Perhaps a benefit of IMRT with intensive chemotherapy will become more apparent with reduced radiation doses. A recently published case study provides detailed input and output dose-volume parameters for a typical IMRT treatment plan using these doses (54).

Future directions include more directed attempts at reducing late xerostomia and swallowing complications by better sparing of the parotids, submandibular glands and oral cavity when feasible. In order to improve post-treatment swallowing function, attempts should also be made to spare the pharyngeal constrictors and the glottic and supraglottic larynx when these structures are not involved with cancer (55). IMRT in advanced head and neck cancer is certainly promising and warrants further study.

\section{Acknowledgments}

This study was supported in part by the University of Chicago/ Northwestern University Oral Cancer Research Center (P50 DE11921-04), University of Chicago Cancer Research 
Center (P30 CA14599), The Francis Lederer Foundation, The Geraldi Norton Memorial Corporation, The Robert and Valda Svendsen Memorial, and Bristol-Myers Squibb, Princeton, New York.

\section{References}

1. Intensity-modulated radiotherapy: current status and issues of interest. Int J Radiat Oncol Biol Phys 51: 880-914, 2001.

2. Eisbruch A, Ten Haken RK, Kim HM, Marsh LH and Ship JA: Dose, volume, and function relationships in parotid salivary glands following conformal and intensity-modulated irradiation of head and neck cancer. Int J Radiat Oncol Biol Phys 45: 577-587, 1999

3. Eisbruch A, Kim HM, Terrell JE, Marsh LH, Dawson LA and Ship JA: Xerostomia and its predictors following parotidsparing irradiation of head-and-neck cancer. Int J Radiat Oncol Biol Phys 50: 695-704, 2001.

4. Dawson LA, Anzai Y, Marsh L, et al: Patterns of localregional recurrence following parotid-sparing conformal and segmental intensity-modulated radiotherapy for head and neck cancer. Int J Radiat Oncol Biol Phys 46: 1117-1126, 2000.

5. Milliken BD, Rubin SJ, Hamilton RJ, Johnson LS and Chen GT: Performance of a video-image-subtraction-based patient positioning system. Int J Radiat Oncol Biol Phys 38: 855-866, 1997.

6. Mell LK, Roeske JC and Mundt AJ: A survey of intensitymodulated radiation therapy use in the United States. Cancer 98: 204-211, 2003.

7. Vokes EE, Kies M, Haraf DJ, et al: Induction chemotherapy followed by concomitant chemoradiotherapy for advanced head and neck cancer: impact on the natural history of the disease. $\mathrm{J}$ Clin Oncol 13: 876-883, 1995.

8. Kies MS, Haraf DJ, Athanasiadis I, et al: Induction chemotherapy followed by concurrent chemoradiation for advanced head and neck cancer: improved disease control and survival. J Clin Oncol 16: 2715-2721, 1998.

9. Mantz CA, Vokes EE, Stenson K, et al: Induction chemotherapy followed by concomitant chemoradiotherapy in the treatment of locoregionally advanced oropharyngeal cancer. Cancer J 7: 140-148, 2001

10. Mantz CA, Vokes EE, Kies MS, et al: Sequential induction chemotherapy and concomitant chemoradiotherapy in the management of locoregionally advanced laryngeal cancer. Ann Oncol 12: 343-347, 2001.

11. Oh JL, Vokes EE, Kies MS, et al: Induction chemotherapy followed by concomitant chemoradiotherapy in the treatment of locoregionally advanced nasopharyngeal cancer. Ann Oncol 14: 564-569, 2003.

12. Stenson KM, Haraf DJ, Pelzer H, et al: The role of cervical lymphadenectomy after aggressive concomitant chemoradiotherapy: the feasibility of selective neck dissection. Arch Otolaryngol Head Neck Surg 126: 950-956, 2000.

13. Vokes EE, Kies MS, Haraf DJ, et al: Concomitant chemoradiotherapy as primary therapy for locoregionally advanced head and neck cancer. J Clin Oncol 18: 1652-1661, 2000.

14. Kies MS, Haraf DJ, Rosen F, et al: Concomitant infusional paclitaxel and fluorouracil, oral hydroxyurea, and hyperfractionated radiation for locally advanced squamous head and neck cancer. J Clin Oncol 19: 1961-1969, 2001.

15. Rosen FR, Haraf DJ, Kies MS, et al: Multicenter Randomized phase II study of paclitaxel (1-hour infusion), fluorouracil, hydroxyurea, and concomitant twice daily radiation with or without erythropoietin for advanced head and neck cancer. Clin Cancer Res 9: 1689-1697, 2003.

16. Vokes EE, Stenson K, Rosen FR, et al: Weekly carboplatin and paclitaxel followed by concomitant paclitaxel, fluorouracil, and hydroxyurea chemoradiotherapy: curative and organpreserving therapy for advanced head and neck cancer. J Clin Oncol 21: 320-326, 2003.

17. Haraf DJ, Rosen F, Stenson K, et al: Weekly carboplatin and paclitaxel followed by concomitant T-FHX with reduced dose XRT for advanced head and nech cancer. Clin Cancer Res 9: 5936-5943, 2003.

18. List MA, Ritter-Sterr C and Lansky SB: A performance status scale for head and neck cancer patients. Cancer 66: 564-569, 1990.
19. List MA, D'Antonio LL, Cella DF, et al: The Performance Status Scale for Head and Neck Cancer Patients and the Functional Assessment of Cancer Therapy-Head and Neck Scale. A study of utility and validity. Cancer 77: 2294-2301, 1996.

20. Browman GP, Levine MN, Hodson DI, et al: The Head and Neck Radiotherapy Questionnaire: a morbidity/quality-of-life instrument for clinical trials of radiation therapy in locally advanced head and neck cancer. J Clin Oncol 11: 863-872, 1993.

21. Lefebvre JL, Chevalier D, Luboinski B, Kirkpatrick A, Collette L and Sahmoud T: Larynx preservation in pyriform sinus cancer: preliminary results of a European Organization for Research and Treatment of Cancer phase III trial. EORTC Head and Neck Cancer Cooperative Group. J Natl Cancer Inst 88: 890-899, 1996.

22. Induction chemotherapy plus radiation compared with surgery plus radiation in patients with advanced laryngeal cancer. The Department of Veterans Affairs Laryngeal Cancer Study Group. N Engl J Med 324: 1685-1690, 1991.

23. Domenge C, Hill C, Lefebvre JL, et al: Randomized trial of neoadjuvant chemotherapy in oropharyngeal carcinoma. French Groupe d'Etude des Tumeurs de la Tete et du Cou (GETTEC). Br J Cancer 83: 1594-1598, 2000.

24. Weissler MC, Melin S, Sailer SL, Qaqish BF, Rosenman JG and Pillsbury HC III: Simultaneous chemoradiation in the treatment of advanced head and neck cancer. Arch Otolaryngol Head Neck Surg 118: 806-810, 1992.

25. Jeremic B, Shibamoto Y, Stanisavljevic B, Milojevic L, Milicic B and Nikolic N: Radiation therapy alone or with concurrent low-dose daily either cisplatin or carboplatin in locally advanced unresectable squamous cell carcinoma of the head and neck: a prospective randomized trial. Radiother Oncol 43: 29-37, 1997

26. Wendt TG, Grabenbauer GG, Rodel CM, et al: Simultaneous radiochemotherapy versus radiotherapy alone in advanced head and neck cancer: a randomized multicenter study. J Clin Oncol 16: 1318-1324, 1998.

27. Brizel DM, Albers ME, Fisher SR, et al: Hyperfractionated irradiation with or without concurrent chemotherapy for locally advanced head and neck cancer. N Engl J Med 338: 1798-1804, 1998.

28. Al-Sarraf M, LeBlanc M, Giri PG, et al: Chemoradiotherapy versus radiotherapy in patients with advanced nasopharyngeal cancer: phase III randomized Intergroup study 0099. J Clin Oncol 16: 1310-1317, 1998.

29. Adelstein DJ, Lavertu P, Saxton JP, et al: Mature results of a phase III randomized trial comparing concurrent chemoradiotherapy with radiation therapy alone in patients with stage III and IV squamous cell carcinoma of the head and neck. Cancer 88: 876-883, 2000.

30. Jeremic B, Shibamoto Y, Milicic B, et al: Hyperfractionated radiation therapy with or without concurrent low-dose daily cisplatin in locally advanced squamous cell carcinoma of the head and neck: a prospective randomized trial. J Clin Oncol 18: 1458-1464, 2000.

31. Calais G, Alfonsi M, Bardet E, et al: Randomized trial of radiation therapy versus concomitant chemotherapy and radiation therapy for advanced-stage oropharynx carcinoma. J Natl Cancer Inst 91: 2081-2086, 1999.

32. Forastiere AA, Goepfert H, Maor M, et al: Concurrent chemotherapy and radiotherapy for organ preservation in advanced laryngeal cancer. N Engl J Med 349: 2091-2098, 2003.

33. Chan AT, Teo PM, Ngan RK, et al: Concurrent chemotherapyradiotherapy compared with radiotherapy alone in locoregionally advanced nasopharyngeal carcinoma: progression-free survival analysis of a phase III randomized trial. J Clin Oncol 20: 2038-2044, 2002.

34. Adelstein DJ, Li Y, Adams GL, et al: An intergroup phase III comparison of standard radiation therapy and two schedules of concurrent chemoradiotherapy in patients with unresectable squamous cell head and neck cancer. J Clin Oncol 21: 92-98, 2003.

35. Fu KK, Pajak TF, Trotti A, et al: A Radiation Therapy Oncology Group (RTOG) phase III randomized study to compare hyperfractionation and two variants of accelerated fractionation to standard fractionation radiotherapy for head and neck squamous cell carcinomas: first report of RTOG 9003. Int J Radiat Oncol Biol Phys 48: 7-16, 2000. 
36. Vokes EE, Weichselbaum RR, Mick R, McEvilly JM, Haraf DJ and Panje WR: Favorable long-term survival following induction chemotherapy with cisplatin, fluorouracil, and leucovorin and concomitant chemoradiotherapy for locally advanced head and neck cancer. J Natl Cancer Inst 84: 877-882, 1992.

37. Haraf DJ, Kies M, Rademaker AW, et al: Radiation therapy with concomitant hydroxyurea and fluorouracil in stage II and III head and neck cancer. J Clin Oncol 17: 638-644, 1999.

38. Garden AS, Harris J, Vokes EE, et al: Preliminary results of Radiation Therapy Oncology Group 97-03: a randomized phase ii trial of concurrent radiation and chemotherapy for advanced squamous cell carcinomas of the head and neck. J Clin Oncol 22: 2856-2864 2004

39. Lee N, Chuang C, Quivey JM, et al: Skin toxicity due to intensity-modulated radiotherapy for head-and-neck carcinoma. Int J Radiat Oncol Biol Phys 53: 630-637, 2002.

40. Mukherji SK, Armao D and Joshi VM: Cervical nodal metastases in squamous cell carcinoma of the head and neck: what to expect. Head Neck 23: 995-1005, 2001.

41. Chao KS, Wippold FJ, Ozyigit G, Tran BN and Dempsey JF: Determination and delineation of nodal target volumes for head-and-neck cancer based on patterns of failure in patients receiving definitive and postoperative IMRT. Int J Radiat Oncol Biol Phys 53: 1174-1184, 2002.

42. Eisbruch A, Foote RL, O'Sullivan B, Beitler JJ and Vikram B: Intensity-modulated radiation therapy for head and neck cancer: emphasis on the selection and delineation of the targets. Semin Radiat Oncol 12: 238-249, 2002.

43. Chao KS, Low DA, Perez CA and Purdy JA: Intensity-modulated radiation therapy in head and neck cancers: The Mallinckrodt experience. Int J Cancer 90: 92-103, 2000.

44. Chao KS, Ozyigit G, Tran BN, Cengiz M, Dempsey JF and Low DA: Patterns of failure in patients receiving definitive and postoperative IMRT for head-and-neck cancer. Int J Radiat Oncol Biol Phys 55: 312-321, 2003

45. Chao KS, Majhail N, Huang CJ, et al: Intensity-modulated radiation therapy reduces late salivary toxicity without compromising tumor control in patients with oropharyngeal carcinoma: a comparison with conventional techniques. Radiother Oncol 61: 275-280, 2001.
46. Sultanem K, Shu HK, Xia P, et al: Three-dimensional intensitymodulated radiotherapy in the treatment of nasopharyngea carcinoma: the University of California-San Francisco experience. Int J Radiat Oncol Biol Phys 48: 711-722, 2000.

47. Lee N, Xia P, Quivey JM, et al: Intensity-modulated radiotherapy in the treatment of nasopharyngeal carcinoma: an update of the UCSF experience. Int J Radiat Oncol Biol Phys 53: 12-22, 2002

48. Lee N, Xia P, Fischbein NJ, Akazawa P, Akazawa C and Quivey JM: Intensity-modulated radiation therapy for headand-neck cancer: the UCSF experience focusing on target volume delineation. Int J Radiat Oncol Biol Phys 57: 49-60, 2003.

49. Butler EB, Teh BS, Grant WH III, et al: Smart (simultaneous modulated accelerated radiation therapy) boost: a new accelerated fractionation schedule for the treatment of head and neck cancer with intensity modulated radiotherapy. Int J Radiat Oncol Biol Phys 45: 21-32, 1999.

50. Teh BS, Mai WY, Grant WH III, et al: Intensity modulated radiotherapy (IMRT) decreases treatment-related morbidity and potentially enhances tumor control. Cancer Invest 20: 437-451, 2002.

51. Eisbruch A, Lyden T, Bradford CR, et al: Objective assessment of swallowing dysfunction and aspiration after radiation concurrent with chemotherapy for head-and-neck cancer. Int J Radiat Oncol Biol Phys 53: 23-28, 2002.

52. Chao KS, Deasy JO, Markman J, et al: A prospective study of salivary function sparing in patients with head-and-neck cancers receiving intensity-modulated or three-dimensional radiation therapy: initial results. Int J Radiat Oncol Biol Phys 49: 907-916, 2001 .

53. Gustin D, Haraf DJ, Stenson K, et al: Treatment of advanced head and neck cancer with induction chemotherapy followed by chemoradiotherapy with reduced radiation dose. J Clin Oncol 22: S14, 2004.

54. Milano MT, Jackson W and Haraf DJ: Piriform sinus: case study. In: Intensity Modulated Radiation Therapy. Mundt AJ and Roeske JR (eds). ON: BC Decker, London, 2005.

55. Eisbruch A, Schwartz M, Rasch C, et al: Dysphagia and aspiration after chemoradiotherapy for head-and-neck cancer: which anatomic structures are affected and can they be spared by IMRT? Int J Radiat Oncol Biol Phys 60: 1425-1439, 2004 